\title{
Avaliação da relação fotoproteção/fotoexposição em acadêmicos do curso de graduação em Medicina na Universidade do Planalto Catarinense - UNIPLAC
}

\author{
Evaluation of the photoprotection/photoexposure relation in academics of the \\ Medicine graduation course at University of Planalto Catarinense - UNIPLAC
}

Luis Felipe Stella Santos ${ }^{1}$, Alexandre Lemos de Souza²

Santos LFS, Souza AL. Avaliação da relação fotoproteção/fotoexposição em acadêmicos do curso de graduação em Medicina na Universidade do Planalto Catarinense - UNIPLAC / Evaluation of the photoprotection/photoexposure relation in academics of the Medicine graduation course at University of Planalto Catarinense - UNIPLAC. Rev Med (São Paulo). 2019 jan.-fev.;98(1):8-15.

RESUMO: O Brasil é um país de ampla extensão territorial e situa-se em uma localização geográfica predominantemente tropical, com altas taxas de radiação solar ao longo de todo o ano. A radiação ultravioleta, presente na luz solar, é responsável por causar malefícios à pele humana, como discromias, irregularidades na epiderme, envelhecimento cutâneo, imunossupressão, alterações no DNA e malignidades. A população jovem vem aumentando a sua representatividade na pirâmide etária nacional e, devido a sua exposição frequente e desprotegida à radiação solar, encontra-se em grande risco aos seus danos. Assim, há que se esclarecer aos jovens, dentre os quais encontram-se os estudantes universitários da área da saúde e de medicina, no que toca a este assunto. Este trabalho analisou os hábitos de vida dos acadêmicos quanto a fotoexposição e a fotoproteção diárias baseando-se na aplicação de um questionário dividido em duas partes: a primeira (questões 1 a 6), relacionada ao perfil socioeconômico do entrevistado e a segunda (questões 7 a 13), a respeito da fotoproteção e da fotoexposição deste. Esta pesquisa foi aprovada pelo número CAAE 67659317.5.0000.5368, do CEP (Comitê de Ética em Pesquisa com Animais e Seres Humanos) 5368 da UNIPLAC. Acadêmicos de todas as séries do curso constituíram a população analisada, somando 94 questionários respondidos de um total de 100. A taxa de perdas e recusas foi de $6 \%$. Participaram maiores de 18 anos, regularmente matriculados no ano de 2017 e em acordo com o TCLE (Termo de Consentimento Livre e Esclarecido). A coleta dos dados e sua análise desenvolveram-se entre os meses de abril e novembro do ano de 2017. Na amostra estudada detectouse a presença de hábitos errôneos no que tange à fotoproteção e exposição à radiação solar. Verificou-se também que a população observada encontra-se mais susceptível ao desenvolvimento de variedades do câncer da pele futuramente.

Descritores: Radiação solar/efeitos adversos; Radiação solar/ prevenção \& controle; Estudantes de medicina.

\begin{abstract}
Brazil is a country of wide territorial extension and is located in a predominantly tropical geographic location, with high rates of solar radiation throughout the year. Ultraviolet radiation, present in sunlight, is responsible for causing human skin damage, such as dyschromia, irregularities in the epidermis, skin aging, immunosuppression, DNA changes and malignancies. The young population has been increasing its representativeness in the national age pyramid and, due to its frequent and unprotected exposure to solar radiation, is at high risk to its damages. Thus, it is necessary to clarify to the youth, among which are the university's students of health and medicine area, about this matter. This work analyzed life's habits of the students regarding daily photoexposure and photoprotection based on the application of a questionnaire divided into two parts: the first one (questions 1 to 6 ), related to the socioeconomic profile of the interviewee and the second one (questions 7 to 13), regarding photoprotection and photoexposure of them. This research was approved by the number CAAE 67659317.5.0000.5368, of the CEP (Committee of Ethics in Research with Animals and Human Beings) 5368 of UNIPLAC. Academics of all the series of the course constituted the analyzed population, leading to 94 questionnaires answered out of 100 . The rate of losses and refusals was $6 \%$. Participants were older than 18 years, regularly enrolled in the year 2017 and in agreement with the FICT (Free and Informed Consent Term). Data collection and analysis were carried out between April and November 2017. The presence of erroneous habits regarding photoprotection and exposure to solar radiation was detected in the sample studied. It has also been found that the observed population is more susceptible to the development of future varieties of skin cancer.
\end{abstract}

Keywords: Solar radiation/adverse effects; Solar radiation/ prevention \& control; Studentes, medical.

Trabalho apresentado no I CONCAT - Congresso Nacional de Ciência, Arte e Tecnologia, Universidade do Planalto Catarinense UNIPLAC; 2017.

1. Discente do curso de graduação em Medicina na Universidade do Planalto Catarinense (UNIPLAC). ORCID: https://orcid.org/00000001-7982-3875. E-mail: felipestella2017@gmail.com.

2. Docente na Universidade do Planalto Catarinense (UNIPLAC). ORCID: https://orcid.org/0000-0003-1187-3272. E-mail: als.bmd@, gmail.com.

Endereço para correspondência: Alexandre Lemos de Souza. Avenida Marechal Castelo Branco, 190. Bairro Universitário - Lages, SC, Brasil.Email: als.bmd@gmail.com. 


\section{INTRODUÇÃO}

exposição diária ao sol de forma desprotegida permite que a radiação ultravioleta (RUV) penetre no organismo humano e cause diferentes formas de danos à saúde. Esta forma de radiação é deletéria a medida que origina, dentre outras comorbidades, irregularidades e aspereza na epiderme, queimaduras, discromias e alterações pigmentares, xerose, telangiectasias, imunossupressão e envelhecimento cutâneo, além de ser a principal responsável pelo desenvolvimento do câncer da pele ${ }^{1}$.

O Brasil é um país com dimensões geográficas bastante extensas, com a maior parte do seu território localizado entre a linha do Equador e trópico de Capricórnio, o que o coloca majoritariamente como um país tropical e, consequentemente, com altas taxas de insolação ao longo das quatro estações do ano. Diante de tamanha vulnerabilidade, é de fundamental importância que seja dada especial atenção no tocante às medidas de prevenção e promoção em saúde a fim de evitar as consequências resultantes do fotodano crônico sofrido pela população ${ }^{1,2}$.

Em nosso país, a neoplasia maligna mais incidente é o câncer da pele. Os do tipo não-melanoma são os responsáveis pelo maior número de casos, muito embora o do tipo melanoma seja o que possui taxa de mortalidade mais elevada. Segundo o Instituto Nacional de Câncer (INCA), para o ano de 2016 a estimativa foi a de que a incidência seria de 80.850 novos casos para o câncer da pele do tipo não melanoma entre os homens e de 94.910 entre as mulheres. Para o câncer da pele do tipo melanoma, a incidência se encontraria em torno de 3.000 e 2.670 casos para homens e mulheres, respectivamente. Tais dados nos colocam em uma posição de alto risco para o desenvolvimento do câncer da pele ${ }^{3}$. A parcela da população que pertence a fototipos maiores (pretos e pardos) possuem naturalmente maiores taxas de produção de melanina, o que é bastante protetor contra o desenvolvimento de malignidades, as quais são menos incidentes se em comparação com a população de pele branca. Porém devese atentar também que são nestes mesmos fototipos em que há maiores taxas de negligência diagnóstica da patologia e em que o mesmo é feito de forma mais tardia, apresentando, portanto, os piores prognósticos ${ }^{4}$.

O processo de carcinogênese está intimamente relacionado com diversos agentes químicos, biológicos e físicos ${ }^{5}$. Dentre estes últimos, se encontram os raios ionizantes, infravermelho e ultravioleta (RUV). A RUV, sobretudo na faixa de 290 a $320 \mathrm{~mm}$, é o principal carcinógeno da pele humana. Ela está dividida, de acordo com a sua frequência e comprimento de onda, em três categorias: UVA (ultravioleta A), UVB (ultravioleta B) e UVC (ultravioleta C), sendo que estas repercutem clinicamente de formas distintas. Os raios UVB são mais carcinogênicos do que os UVA. A radiação ultravioleta $\mathrm{C}$ não atravessa a ionosfera, não atingindo, portanto, o ser humano. O efeito carcinogênico é cumulativo. O processo de desenvolvimento do câncer da pele é favorecido tanto pela radiação UVA como pela radiação UVB, todavia, com mecanismos bastante diferentes. Se por um lado a radiação ultravioleta A penetra intensamente na pele e interage tanto com os queratinócitos epidérmicos quanto com os fibroblastos da camada dérmica, causando o envelhecimento cutâneo, a radiação ultravioleta B leva ao processo de mutação no DNA dos queratinócitos da camada da epiderme e é supressora do sistema imune cutâneo. A cancerização ocorre devido a uma alteração cromossomial que leva a um processo multissequencial envolvendo a ativação sucessiva de oncogenes e/ou a inativação de genes supressores, levando ao crescimento desordenado das células. Organismos com sistema imune deficiente ou pouco atuante estarão mais propensos à carcinogênese. Ambos os espectros são capazes de levar a alterações benéficas e maléficas, sendo estas dependentes da intensidade da radiação solar (latitude, áreas do corpo expostas, vestimentas, profissão) e da cor da pele (fototipo) $)^{5,6,7}$.

Assim, a principal medida a ser adotada é a fotoproteção. $\mathrm{O}$ câncer da pele detém altas taxas de incidência, com importante projeção de aumento das mesmas. Porém, o mesmo pode e deve ser evitado através de medidas preventivas a serem adotadas. A faixa etária referente aos jovens deve ser alvo de conscientização, pois usualmente é a parcela da população que permanece exposta ao sol por maior tempo no cotidiano, pela execução das suas atividades diárias e atividades de lazer ${ }^{6,7}$.

Muito embora a exposição solar represente o principal fator de risco para o desenvolvimento do câncer da pele, o número de nevos melanocíticos, a história familiar e a susceptibilidade genética também estão associados aos casos de melanoma. Ademais, a presença de história pessoal de melanoma, eleva substancialmente o risco de um novo episódio da doença, desenvolvendo múltiplos melanomas primários, o que ocorre em até $8 \%$ dos pacientes nestas circunstâncias ${ }^{7}$.

Observando-se este cenário, deparamo-nos com a realidade de que há, no presente, um grande incremento no número de casos novos de câncer da pele em nosso país. O objetivo desse trabalho foi verificar o conhecimento e os hábitos de vida dos acadêmicos do curso de graduação em Medicina quanto aos fatores de fotoexposição e fotoproteção e seu conhecimento acerca do assunto.

\section{MATERIAIS E MÉTODOS}

Trata-se de um estudo epidemiológico, descritivo e transversal. A presente pesquisa foi realizada através da aplicação de um questionário respondido pelos acadêmicos do curso de medicina da Universidade do Planalto Catarinense - UNIPLAC-, contendo 13 questões a respeito de hábitos de exposição solar e de fotoproteção, sendo este 
dividido em duas partes: a primeira, que coletou dados a respeito do perfil socioeconômico do aluno participante e a segunda, que obteve os dados referentes à fotoproteção e fotoexposição do mesmo. Puderam participar da pesquisa os acadêmicos com idade superior a 18 anos, regularmente matriculados no curso de medicina da UNIPLAC no ano de 2017 e que assinaram o TCLE (Termo de Consentimento Livre e Esclarecido). A participação possui caráter voluntário e sem acarretar qualquer dano ao participante. A coleta de dados e a sua análise desenvolveram-se entre os meses de abril e novembro do ano de 2017. Objetivou-se entrevistar 100 acadêmicos do curso, com taxa de adesão de $60 \%$ dos alunos convidados. Os questionários foram respondidos por estudantes de todas as séries do curso que atenderam aos critérios de inclusão. O presente trabalho foi aprovado pelo número CAAE 67659317.5.0000.5368, do CEP (Comitê de Ética em Pesquisa com Animais e Seres Humanos) 5368 - Universidade do Planalto Catarinense - UNIPLAC.

\section{RESULTADOS}

Após a conclusão da aplicação dos questionários, 94 acadêmicos do curso de Medicina da UNIPLAC (Universidade do Planalto Catarinense), de todas as séries, participaram da pesquisa. Destes, $59,57 \%$ eram do sexo feminino e $40,42 \%$ do sexo masculino (Gráfico 1). A taxa de perdas e recusas foi de $6 \%$.

Gráfico 1. Proporção de gênero entre os entrevistados

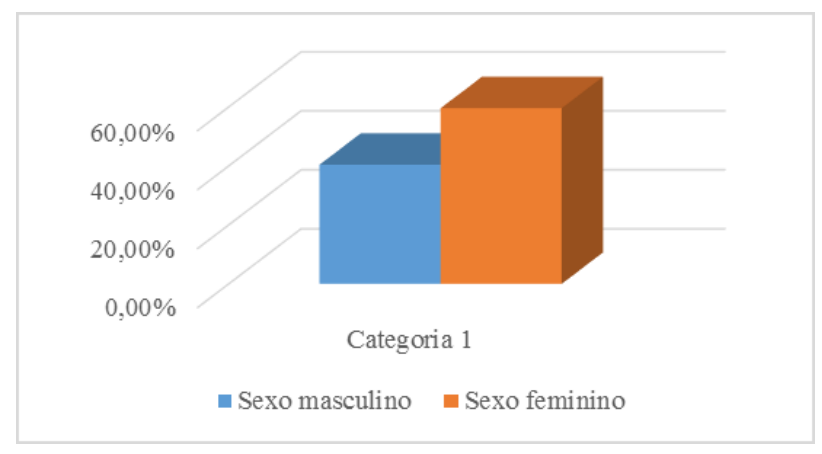

Dentre os participantes, houve um predomínio de jovens, com amplitude variante entre 18 até mais de 30 anos de idade. A maior parte dos entrevistados encontrouse entre 20 e 25 anos $(59,57 \%)$.

No tocante a renda familiar média, conforme o Gráfico 2, 17,02\% afirmaram possuir renda de até $r \$$ $5000,00,34,02 \%$ entre $r \$ 5000,00$ e $10000,00,36,17 \%$ entre r\$ 100000,00 e 20000,00 e $12,76 \%$ acima de r\$ 20000,00 .

Dentre os 94 respondentes, 54,25\% possuíam plano de saúde privado e $25,53 \%$ possuíam algum familiar que já teve câncer da pele, enquanto que apenas $1,06 \%$ já desenvolveu a doença em algum momento da vida. Utilizou-se como base a classificação de tom da pele elaborada por Thomas B. Fitzpatrick para resolução da questão referente ao fototipo do participante, a qual distribui-se da seguinte maneira: fototipo I - branca (pele muito clara, sempre queima, nunca bronzeia); fototipo II - branca (pele clara, sempre queima e às vezes bronzeia); fototipo III - morena clara (pele menos clara, algumas vezes queima e sempre bronzeia); fototipo IV - morena moderada (pele morena clara, raramente queima e sempre bronzeia); fototipo $\mathrm{V}$ - morena escura (pele morena escura, nunca queima e sempre bronzeia); fototipo VI - negra (pele negra, nunca queima, sempre bronzeia $)^{8}$.

De acordo com o Gráfico 3, quanto ao fototipo dos acadêmicos que participaram da pesquisa, pode-se verificar que houve predomínio dos tipos II, III e IV, responsáveis por $35,10 \%, 28,72 \%$ e $25,53 \%$ da amostra avaliada, respectivamente. $10,63 \%$ são ainda do fototipo I enquanto que os fototipos V e VI não tiveram representantes dentre os participantes.

Gráfico 2. Renda familiar média dos acadêmicos participantes

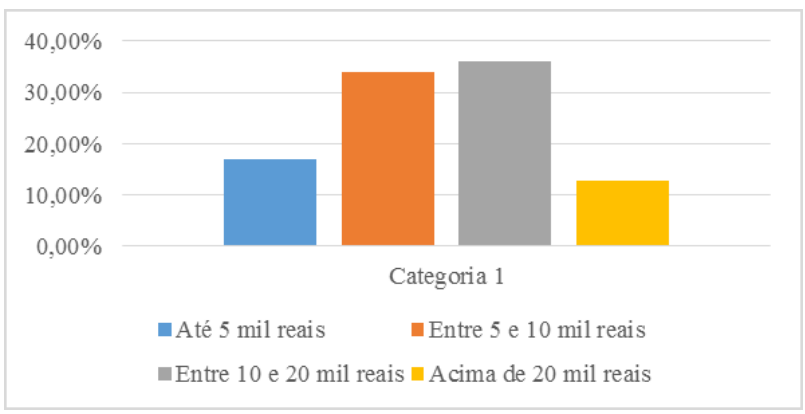

Gráfico 3. Fototipo dos participantes, segundo classificação de Fitzpatrick, 1988. Fototipo I - branca (pele muito clara, sempre queima, nunca bronzeia); fototipo II - branca (pele clara, sempre queima e às vezes bronzeia); fototipo III - morena clara (pele menos clara, algumas vezes queima e sempre bronzeia); fototipo IV - morena moderada (pele morena clara, raramente queima e sempre bronzeia); fototipo $\mathrm{V}$ - morena escura (pele morena escura, nunca queima e sempre bronzeia); fototipo VI - negra (pele negra, nunca queima, sempre bronzeia)

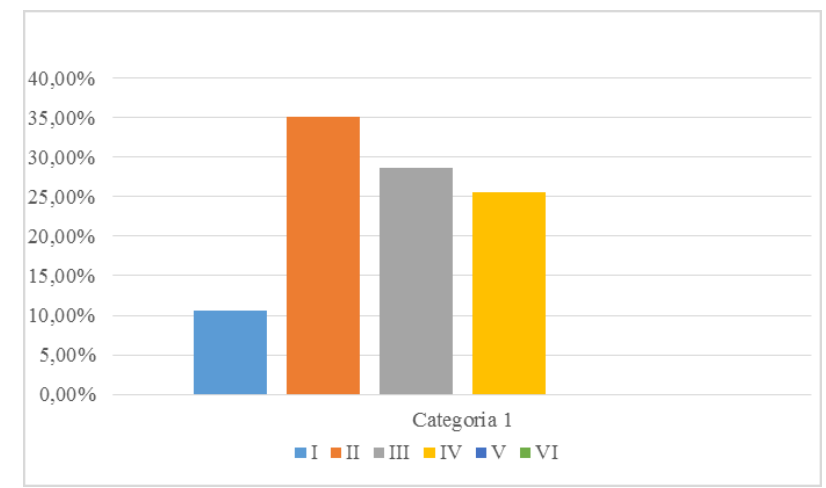


Santos LFS, Souza AL. Avaliação da relação fotoproteção/fotoexposição em acadêmicos do curso de graduação.

Com relação aos hábitos de exposição solar, 48 dos entrevistados $(51,06 \%)$ negou ter o hábito de se bronzear. Todavia, conforme demonstrado no Gráfico 4, dentre os 46 restantes $(48,93 \%)$, que afirmaram realizar a prática, $39(84,78 \%)$ afirmaram utilizar a exposição ao sol para tal, enquanto que apenas $1(2,17 \%)$ participante faz uso de autobronzeadores, $1(2,17 \%)$ realiza bronzeamento artificial e outro $(2,17 \%)$ ainda selecionou as duas primeiras opções (exposição ao sol e uso de autobronzeadores) para conseguir bronzear-se.

Gráfico 4. Métodos utilizados para bronzeamento

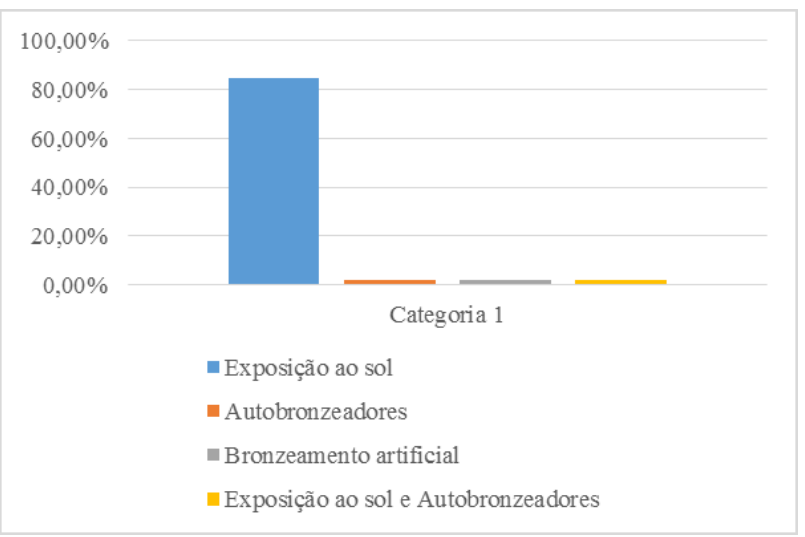

Quanto ao horário em que a exposição solar acontece, houve predomínio de períodos inadequados, pois apenas $28,72 \%$ dos entrevistados costuma expor-se ao sol antes das 10 horas da manhã e/ou após às 16:00 horas. Em contrapartida, 71,27\%, mais de dois terços da amostra em estudo, expõe-se ao sol em horários de maior insolação e, consequentemente, com maiores riscos para a pele.
No referente a fotoproteção, somente 30 dos participantes $(31,91 \%)$ utilizam o filtro solar como forma de proteção diária e $64(68,08 \%)$ participantes afirmaram não ter a prática diária, conforme segue Gráfico 5:

Gráfico 5. Uso diário do filtro solar

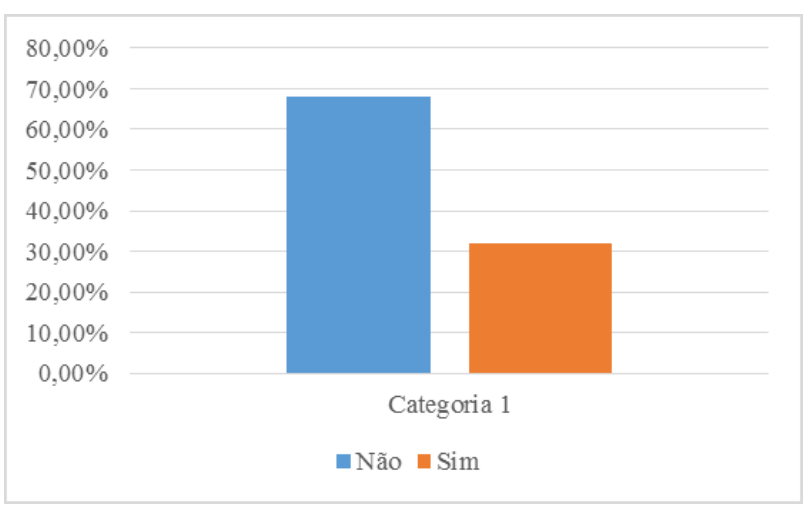

Dentre os entrevistados que aplicam o filtro solar diária ou eventualmente, $1,06 \%$ reaplica o filtro solar a cada duas horas, $5,31 \%$ a cada 4 horas e 4,25 sempre que transpiram intensamente. $30,85 \%$ aplicam o filtro solar apenas uma vez, sem reaplicar ao longo do dia e a grande maioria, 58,51\%, não aplica o filtro solar no cotidiano.

De acordo com o Gráfico 6, durante a exposição solar, independentemente de utilizar o filtro solar, 19,14\% afirmaram utilizar roupas como medida protetiva. Em segundo plano, 2,12\% afirmaram usar bonés/chapéus e $32,97 \%$, óculos de sol. Combinando mais de uma opção, $2,12 \%$ selecionaram as duas primeiras, $10,13 \%$ a primeira e a terceira, $18,08 \%$ as duas últimas e $8,51 \%$ as três formas. Houve ainda $6,38 \%$ dos respondentes que afirmaram não utilizar outras formas de proteção.

Gráfico 6. Outros meios de fotoproteção

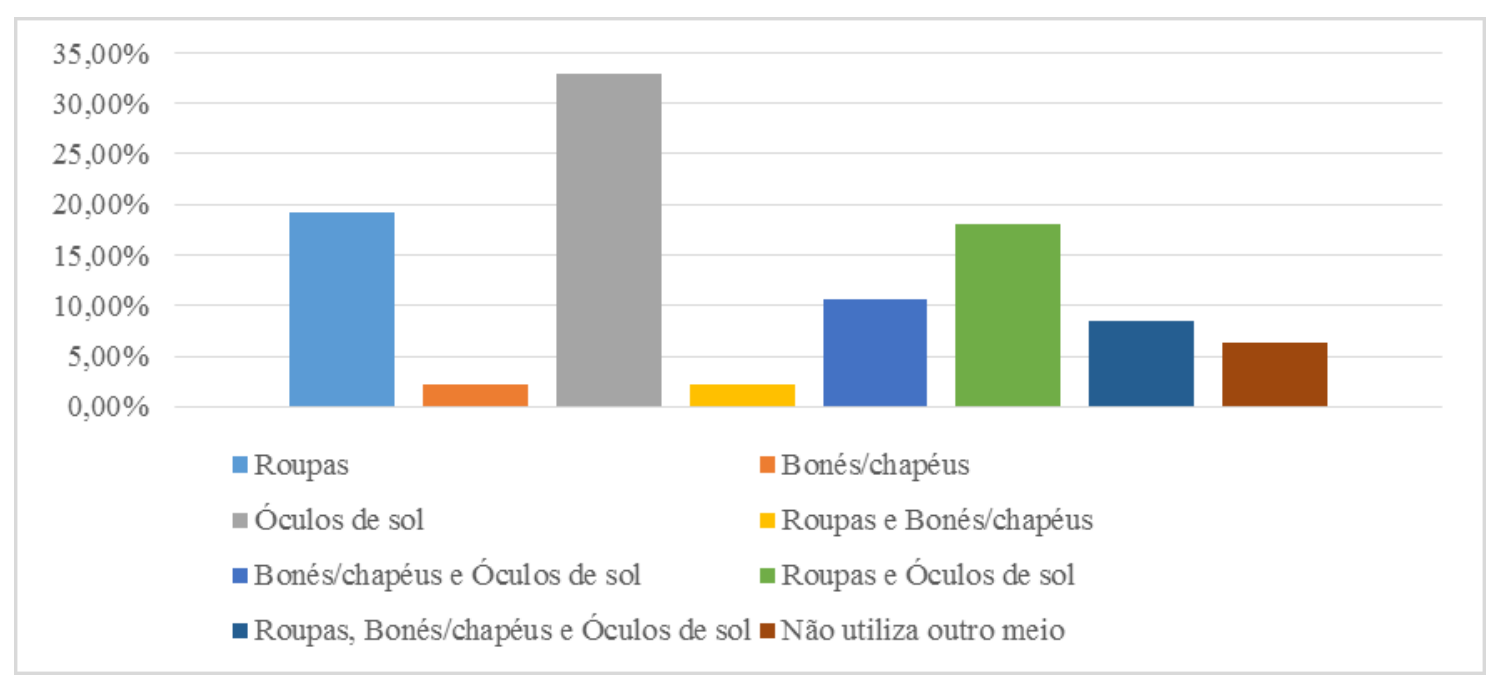


Por fim, em situações de veraneio, como ir à praia, $91(96,80 \%)$ dos 94 entrevistados afirmou utilizar o filtro solar ao menos uma vez. Destes, $75,82 \%$ o fazem 30 minutos antes da exposição $20,21 \%$ ao chegar na praia, $2,19 \%$ algum tempo após ter chegado na praia (02_2,19\%) e ainda $1,06 \% 30$ minutos antes e novamente após chegar à praia. $18,68 \%$ afirmam não reaplicar o filtro solar durante o passeio, entretanto, dentre aqueles que reaplicam, o fazem cada 2 horas, em 34,78\% dos casos, a cada 4 horas, em $20,21 \%$ dos casos, ou sempre que há transpiração intensa ou contato coma a água, em $34,06 \%$.

\section{DISCUSSÃO}

O efeito da radiação solar na pele humana é deletério e cumulativo. Cada organismo responde individualmente aos insultos solares e a recuperação deste aos mesmos depende, dentre outros fatores, do fototipo e, consequentemente, da concentração de melanina presente nos queratinócitos da pele exposta ao fotodano ${ }^{5,9}$.

Estudo realizado com 450 acadêmicos de medicina de diferentes universidades, observou-se que, no geral, os horários preferidos para a exposição solar por esta população foram após as 16 horas $(34,8 \%)$, seguido do período entre as 10 e 16 horas $(31,5 \%)$. Contrariamente, o presente trabalho demonstrou que $71,27 \%$ da amostra analisada expõe-se ao sol em períodos de maior risco para a saúde e com maiores taxas de incidência da radiação ultravioleta (entre as 10 e 16 horas). O estudo analisado destaca ainda que $36,5 \%$ dos estudantes utilizam o protetor solar de forma diária e 50,3\% ao longo do verão, além de haver histórico pessoal positivo para neoplasia de pele em $1,5 \%$ dos alunos. Neste trabalho, apenas 31,91\% dos entrevistados afirmaram utilizar o filtro solar diariamente enquanto que $68,08 \%$, mais de dois terços da amostra, não o utilizam. O histórico familiar foi positivo em $25,53 \%$ dos participantes ao passo que $1,06 \%$ já desenvolveu a doença ${ }^{10}$.

Outro estudo realizado com acadêmicos de diferentes cursos de graduação em uma universidade pública no estado de São Paulo (BR) examinou que $22,1 \%$ expõem-se intencionalmente ao sol objetivando o bronzeamento, ao mesmo tempo que $70,9 \%$ afirmaram adotar algum tipo de medida fotoprotetiva (filtro solar, busca pela sombra, uso de vestimenta, uso de óculos, chapéu ou boné e uso de sombrinha) e $44 \%$ utilizam filtro solar associado a pelo menos outra medida. Paralelamente, este trabalho constatou que, dentre os respondentes, $19,14 \%$ afirmaram utilizar roupas como medida protetiva, 2,12\% bonés/chapéus e 32,97\%, óculos de sol. Além de 6,38\% dos participantes que afirmaram não utilizar outras formas de proteção ${ }^{11}$.

No que toca aos profissionais já graduados e em exercício da profissão, a realidade demonstra-se ainda mais preocupante se comparada com a desta pesquisa. De acordo com uma pesquisa que entrevistou exclusivamente profissionais médicos, pode-se verificar que mais de um quinto dos mesmos possui o hábito de expor-se ao sol em horários inadequados e de maiores riscos para o desenvolvimento do câncer da pele, além de menos da metade da população estudada utilizar o protetor solar de forma diária, apesar do conhecimento dos malefícios desta prática. $\mathrm{O}$ trabalho demonstrou ainda que a exposição ao sol em $61 \%$ dos entrevistados era feita de maneira diária e inadequada, o que é ainda mais preocupante, pois trata-se de um grupo de profissionais suficientemente esclarecidos acerca do tema ${ }^{12}$.

Outros estudos corroboram ainda mais com este panorama e apontam a carência de informações como fator agravante deste cenário ${ }^{13}$. Em estudo realizado com acadêmicos do curso de enfermagem, do primeiro e último anos, pode-se averiguar que tanto o conhecimento dos alunos da primeira série era menor como o risco comportamental para o desenvolvimento de uma neoplasia cutânea era maior, pois expunham-se ao sol em períodos de maiores taxas de radiação ultravioleta, se comparados aos alunos da série final do curso. Os autores atribuem tal fato ao menor conhecimento a respeito do tema por parte daqueles em relação a estes. Todavia, concluem também que deveria haver expansão deste conhecimento em ambos os grupos de alunos ${ }^{14}$.

Analogamente, outro trabalho chama a atenção ainda para o fato de que, embora cientes dos benefícios do uso do filtro solar e dos prejuízos da sua não utilização, muitos acadêmicos da área da saúde o utilizam como principal medida fotoprotetora, embora de forma errônea ${ }^{15}$. Em contrapartida, este trabalho avaliou que os estudantes do curso de medicina da UNIPLAC não possuem esta consciência ao longo do cotidiano, tendo as suas ações fotoprotetoras concentradas em situações de veraneio e ainda assim não executadas de forma totalmente correta. Observou-se também no trabalho que a maioria dos universitários se expõe excessivamente ao sol, em horários de maior risco e sem a utilização de medidas fotoprotetoras, o que reforça os resultados da presente pesquisa ${ }^{15}$.

\section{Fotoprevenção}

Pesquisa conduzida por Pereira de Souza ${ }^{16}$ estimou que os valores médios para custear o tratamento dos cânceres da pele do tipo não-melanoma são inferiores aos gastos com o melanoma cutâneo. Ademais, o estudo colocou ainda que, para o sistema de saúde privado os gastos totais encontram-se reduzidos, o que deve-se majoritariamente a maior prevenção e tratamento de lesões pré-malignas em estágio iniciais, gerando redução significativa de custos.

Estudos convergem ao concluir que a prevenção é a melhor saída para não onerar os sistemas públicos de saúde e poupar os cofres públicos ${ }^{17,18}$.

Hollestein e Nijsten ${ }^{17}$ executaram um estudo envolvendo pesquisadores do mundo todo em mais de 50 países para avaliar os impactos das doenças de pele em 
diferentes locais e a nível global. O trabalho concluiu que as condições da saúde da pele colocam um grande peso nos sistemas de saúde em todo o mundo e a prevenção deve ser a medida priorizada ${ }^{17}$. O impacto das doenças de pele vem crescendo ao longo dos últimos anos, portanto há que se pensar em estratégias de prevenção a nível global em caráter de urgência ${ }^{18}$.

Estudos australianos que também avaliaram a situação no estado de Nova Gales do Sul (AUS) apontam que a conscientização dos profissionais e pacientes é fundamental, posto que a redução da incidência de casos da patologia é o melhor caminho a ser seguido, reduzindo assim os custos diretos e indiretos que a doença implica ${ }^{19,20}$.

A relação custo benefício é clara: utilizar verba para conscientizar a população e, desta forma, levar a mudanças de comportamento, reduzem a mortalidade, a morbidade e os gastos com as patologias relacionadas ao fotodano crônico, como, principalmente o câncer da pele. Assim, há benefícios também monetários com tais medidas ${ }^{20}$.

Ao longo dos últimos anos, ainda que em menor escala, os índices epidemiológicos de incidência do câncer da pele tipo melanoma vem apresentando elevação constante. Esta situação não se verifica apenas em nosso país, mas sim em todo o mundo, fato que levou a hipótese criada por pesquisadores estadunidenses de que estamos vivendo uma "epidemia do melanoma". Os autores atribuem ao diagnóstico precoce e às novas técnicas de desmatoscopia, que permitem melhor qualidade diagnóstica, com maior precisão e em estágios iniciais das lesões, como os principais fatores para tal situação ${ }^{21}$. Entretanto, há que se raciocinar se esta elevação nos índices é realmente condizente aos novos casos verdadeiros de melanoma ou apenas o resultado do desenvolvimento de melhores tecnologias aplicadas à saúde e do avanço no que se refere ao rastreio da doença, computando hoje os casos que outrora foram subdiagnosticados ${ }^{22,23}$. É de fundamental importância que o médico generalista tenha a capacidade de realizar o exame clínico detalhado e indicar a biópsia quando suspeitar de melanoma ${ }^{7,22,24}$. Um estudo austríaco demonstrou ainda como pode ser grande o viés epidemiológico do melanoma, pois em alguns países, dentre os quais se inclui a Áustria, o registro de casos da doença não é obrigatório para os hospitais particulares e para a saúde privada no Registro Nacional de Câncer (National Cancer Registry) ${ }^{24}$.

Trabalhos apontam que há carência de informação no que se refere aos riscos da fotoexposição contínua e desprotegida ${ }^{25 ; 26,27}$. Em estudo realizado com pacientes atendidos no ambulatório médico de especialidades em uma universidade do sul do estado de Santa Catarina (BR), averiguou-se que há falta de informação sobre o tema, sendo necessário elaborar campanhas de incentivo à fotoproteção, sem limitar-se, contudo, ao uso de protetor solar, mas sim atuar na educação em saúde de forma ampla e irrestrita de modo a modificar os hábitos de vida dos pacientes atendidos ${ }^{27}$.

Pesquisas revelam que as medidas fotoprotetoras são bastante discrepantes de acordo com o local, faixa etária e condição socioeconômica analisada ${ }^{25,26,27,28,29}$.

Em estudo realizado com trabalhadores de rua, constatou-se que, muito embora 92\% dos entrevistados tivessem a consciência de que a radiação ultravioleta é extremamente deletéria e a grande responsável pelo processo de carcinogênese do câncer da pele, apenas $26 \%$ destes utilizavam o filtro solar como medida preventiva conforme orienta a Sociedade Brasileira de Dermatologia $(\mathrm{SBD})^{1,28}$. Outro estudo realizado com trabalhadores de praia averiguou ainda que estes estão expostos à radiação ultravioleta solar de forma diária, contínua e desprotegida ao longo de todo o período de suas atividades laborativas, o que coloca esta parcela da população em uma situação de risco ainda maior para o desenvolvimento de neoplasias cutâneas $^{29}$. A exposição solar desprotegida foi superior a do presente estudo em ambos os trabalhos, o que pode estar relacionado ao maior grau de instrução e conhecimento acerca do tema por parte dos acadêmicos de medicina se comparado às amostras de trabalhadores pesquisadas.

Campanhas realizadas ao longo dos últimos anos por diferentes classes profissionais da área da saúde buscaram promover a conscientização da população em diferentes estados brasileiros sobre a importância da utilização diária e de forma correta das medidas fotoprotetoras como a principal forma de profilaxia de novos casos de câncer da pele ${ }^{30,31,32}$.

\section{CONCLUSÃO}

Nesta amostra detectou-se a presença de hábitos irregulares e inadequados no referente à exposição à radiação solar e ao uso das medidas fotoprotetivas ficando, portanto, a população estudada mais susceptível ao desenvolvimento de variedades do câncer da pele futuramente. 


\section{REFERÊNCIAS}

1. Schalka S, Steiner D. Consenso Brasileiro de Fotoproteção da Sociedade Brasileira de Dermatologia. Disponível em: http://issuu.com/sbd.br/docs/consensob.fotoproteoleigoweb? $=0 / 6449812$.

2. Melo MM, Ribeiro CSDC. Novas considerações sobre a fotoproteção no Brasil: revisão de literatura. Rev Ciên Saúde. 2015;5(3):80-96. doi: http://dx.doi.org/10.21876/ resfmit. v5i3.375.

3. Instituto Nacional de Câncer (INCA) José Alencar Gomes da Silva. Estimativa 2016 - Incidência de câncer no Brasil. INCA. Disponível em: http://www.inca.gov.br/ estimativa/2016/tabelaestados.asp?UF=BR.

4. Oma, N, Buster K, Sanchez M, Hernandez C, Kundu RV, Chiu M, Roberts WE, Draelos ZD, Bhushan R, Taylor SC, Lim HW. Skin cancer and photoprotection in people of color: A review and recommendations for physicians and the public. J Am Acad Dermatol. 2014; 70(4):748-62. doi: http://dx.doi. org/10.1016/j.jaad.2013.11.038.

5. Azulay RD. Dermatologia. Rio de Janeiro: Guanabara Koogan; 2013.

6. Corrêa MP, Pires LCM. Doses of erythemal ultravioleta radiation observed in Brazil. Int J Dermatol. 2013;52(8):96673. doi: 10.1111/j.1365-4632.2012.05834.x.

7. Rastrelli M, Tropea S, Rossi CR, Alaibac M. Melanoma: epidemiology, risk factors, pathogenesis, diagnosis and classification. In Vivo. 2014;28(5):1005-11. doi: 0258$851 \mathrm{X} / 2014$.

8. Fitzpatrick TB. The validity and practicality of sun-reactive skin types I through VI. Arch Dermatol. 1988;124(6):869-71.

9. Wolff K, Johnson RA, Saavedra AP. Dermatologia de Fitzpatrick. Rio Grande do Sul: AMGH Editora Ltda; 2015.

10. Purim KSM, Wroblevski FC. Exposição e proteção solar dos estudantes de medicina de Curitiba (PR). Rev Bras Educ Med. 2014;38(4):477-85. doi: 10.1590/S010055022014000400009.

11. Urasaki MB, Murad MM, Silva MT, Maekawa TA, Zonta GM. Exposure and sun protection practices of university students. Rev Bras Enferm. 2016;69(1):114-21. doi: 10.1590/00347167.2016690117i.

12. Purim KSM, Franzoi CF. Hábitos solares e fotoproteção de médicos - estudo exploratório. Rev Med Res. 2014;16(2):8998. Disponível em: http://www.crmpr.org.br/publicacoes/ cientificas/index.php/revista-do-medico-residente/ article/ view/594/579.

13. Silva ALA, Sousa KRF, Silva AF, Fernandes ABF, Matias VL, Colares AV. A importância do uso de protetores solares na prevenção do fotoenvelhecimento e câncer de pele. Rev Interfaces. 2015;3(1):2-8. doi: 10.16891/2317. 434X.143.

14. Ylmaz M, Yavuz B, Subasi M, Kartal A, Celebioglu A, Kacar H, Adana F, Ozyurek P, Altiparmak S. Skin cancer knowledge and sun protection behavior among nursing students. Jpn J Nurs Sci. 2015;12(1):69-78. doi: 10.1111/jjns.12049.

15. Nunes, HL, Limonta IDC, Vieira JFL, Borges VS. Avaliação dos hábitos e conhecimento dos estudantes da área de saúde sobre a fotoexposição e uso do protetor solar. Conexão Ci. 2017;12(1):28-37. doi: 10.24862/cco.v12i1.552.

16. Souza RJSP, Mattedi AP, Rezende ML, Corrêa MP, Duarte
EM. Estimativa do custo do tratamento do câncer de pele tipo não-melanoma no Estado de São Paulo - Brasil. An Bras Dermatol. 2011;86(4):657-62. doi: 10.1590/S036505962009000300004.

17. Hollestein, LM; Nijsten, T. An Insight into the Global Burden of Skin Diseases. J Invest Dermatol. 2014;134(6):1499-501. doi:10.1038/jid.2013.513.

18. Hay RJ, Johns NE, Williams HC, Bolliger IW, Dellavalle RP, Margolis DJ, Marks R, Naldi L, Weinstock MA, Wulf SK, Michaud C, J L Murray C, Naghavi M. The global burden of skin disease in 2010: an analysis of the prevalence and impact of skin conditions. J Invest Dermatol. 2014;134:1527-34. doi: 10.1038/jid.2013.446.

19. Doran CM, Ling R, Byrnes J, Crane M, Shakeshaft AP, Searles A, Perez D. Benefit Cost Analysis of Three Skin Cancer Public Education Mass-Media Campaigns Implemented in New South Wales, Australia. PLoS ONE. 2016;11(1):1-10. doi: 10.1371/journal.pone.0147665.

20. Doran CM, Ling R, Byrnes J, Crane M Searles A, Perez D, Shakeshaft AP. Estimating the economic costs of skin câncer in New South Wales, Australia. BMC Public Health. 2015;15(952):1-10. doi: 10.1186/s12889-015-2267-3.

21. Weyers W. The 'epidemic' of melanoma between underand over diagnosis. J Cutan Pathol. 2012;39:9-16. doi: 10.1111/j.1600-0560.2011.01831.x.

22. Higgins HW, Lee KC, Galan A, Leffell DJ. Melanoma in situ: part I. Epidemiology, screening, and clinical features. J Am Acad Dermatol. 2015;73(2):181-90. doi: 10.1016/j. jaad.2015.04.014.

23. Frangos JE, Duncan LM, Piris A, et al. Increased diagnosis of thin superficial spreading melanomas: A 20-year study. J Am Acad Dermatol. 2012;67(3):387-94. doi: 10.1016/j. jaad.2011.10.026.

24. Monshi B, Vujic M, Kivaranovic D, et al. The burden of malignant melanoma-lessons to be learned from Austria. Eur J Cancer. 2016;56:45-53. doi: 10.1016/j.ejca.2015.11.026.

25. Fabris MR, Duares ES, Martignago BC, Blanco LF, Fabris TR. Assessment of knowledge of skin cancer prevention and its relation with sun exposure and photo protection amongst gym academy members on the south of Santa Catarina, Brazil. An Bras Dermatol. 2012;87(1):36-43. doi: 10.1590/S036505962012000100004.

26. Margotto FS, Silva HP, Meireles RS, Neugebauer MGFP, Abrahao GF, Rauber J L. Fotoexposição e fatores de risco para câncer de pele: avaliação de hábitos e conhecimentos da população participante da campanha de prevenção ao câncer de pele em Morro Redondo/RS . Rev AMRIGS. 2016;60(1):32-7. Disponível em: https:/www. amrigs.org/revista/7.

27. Bardini G, Lourenço D, Fissmer, MC. Avaliação do conhecimento e hábitos de pacientes dermatológicos em relação ao câncer da pele. Arq Catarin Med. 2012;41(2):5663. Disponível em: http://www.acm.org.br/revista/pdf/ artigos/929.pdf.

28. Pompeu GF, Bortolança PC, Grignoli CRE, Simionato MIV, Grignoli LCE. Estudo comparativo sobre a conscientização dos hábitos de fotoproteção e dos fatores de risco da carcinogênese de pele em trabalhadores de rua. Rev Cien UNIARARAS. 2013;1(2):54-64. Disponível em: http:// 
Santos LFS, Souza AL. Avaliação da relação fotoproteção/fotoexposição em acadêmicos do curso de graduação.

www.uniararas.br/revistacientifica/ documentos/art.7-0042013.pdf.

29. Meyer PF, Silva RMV, Carvalho MGF, Nobrega MM, Aires FS, Oliveira AGGB, et al. Investigação sobre a exposição solar em trabalhadores de praia. Rev Bras Promoç Saúde. 2012;25(1):103-9. doi: 10.5020/18061230.2012.p103.

30. Silva CV, Cardoso AST, Dallaqua B, Pereira FA, Cazedey ECL. Campanha de fotoeducação: orientações à população de Salvador-BA por estudantes de farmácia. Rev UFG. 2015;15(16):77-89. doi: https://doi.org/10.5216/revufg. v15i16.48534.
31. Siqueira CG, Forgerini M, Rascado RR, Marques LA. Núcleo de Atenção Farmacêutica da UNIFAL-MG (NAFAU). Rev Univ Vale do Rio Verde. 2016;14(2):1079-83. doi: 10.5892/ ruvrd.v14i2.3168.

32. Silva ROA, Rocha JA, Monteiro DTP, Marques $L A M$. Quem se ama, protege sua pele: orientações farmacêuticas na prevenção contra o câncer de pele. Rev Conexão UEPG. 2017;13 (2) 306-15. doi: http://dx.doi.org/10.5212/Rev. Conexao.v.13.i2.0008.

Recebido: 27.11.17

Aceito: 28.01.19 